\title{
Aspherical-Atom Modeling of Coordination Compounds by Single-Crystal X-ray Diffraction Allows the Correct Metal Atom To Be Identified
}

\author{
Birger Dittrich, ${ }^{*[a, b]}$ Claudia M. Wandtke, ${ }^{[b]}$ Alke Meents, ${ }^{[c]}$ Kevin Pröpper, $^{[b]}$ \\ Kartik Chandra Mondal, ${ }^{[b]}$ Prinson P. Samuel, ${ }^{[b]}$ Nurul Amin SK, ${ }^{[b]}$ Amit Pratap Singh, \\ Herbert W. Roesky, ${ }^{[b]}$ and Navdeep Sidhu ${ }^{[b]}$
}

Dedicated to Professor M. A. Spackman on the occasion of his 60 th birthday

\begin{abstract}
Single-crystal X-ray diffraction (XRD) is often considered the gold standard in analytical chemistry, as it allows element identification as well as determination of atom connectivity and the solid-state structure of completely unknown samples. Element assignment is based on the number of electrons of an atom, so that a distinction of neighboring heavier elements in the periodic table by XRD is often difficult. A computationally efficient procedure for aspherical-atom least-squares refinement of conventional diffraction data of organometallic compounds is proposed. The iterative procedure is conceptually similar to Hirshfeld-atom refinement (Acta Crystallogr. Sect. A
\end{abstract}

2008, 64, 383-393; IUCrJ. 2014, 1,61-79), but it relies on tabulated invariom scattering factors (Acta Crystallogr. Sect. B 2013 69, 91-104) and the Hansen/Coppens multipole model; disor dered structures can be handled as well. Five linear-coordinate $3 \mathrm{~d}$ metal complexes, for which the wrong element is found if standard independent-atom model scattering factors are relied upon, are studied, and it is shown that only aspherical-atom scattering factors allow a reliable assignment. The influence of anomalous dispersion in identifying the correct element is in vestigated and discussed.

\section{Introduction}

Element assignment in single-crystal $\mathrm{X}$-ray diffraction (XRD) is based on the number of electrons of a particular atom, so that neighboring elements in the periodic table are often hard to distinguish by using this method. Two-coordinate 3d-block carbene complexes ${ }^{[1-7]}$ with the cyclic alkylaminocarbene (CAAC) ligand 3,3,5,5-tetramethyl-1-(2,6-diisopropylphenyl)pyrrolidine2-ylidene (see scheme in Figure 1) provide examples in which the situation is even worse: the use of the independent atom model (IAM) leads to significantly better figures of merit for the element to the left ${ }^{1}$ of the correct one in the periodic table, and the element can hence not be identified by XRD by

[a] Dr. B. Dittrich

Institut für Anorganische und Angewandte Chemie

Universität Hamburg

Martin-Luther-King-Platz 6

20146 Hamburg (Germany)

E-mail:birger.dittrich@chemie.uni-hamburg.de

[b] Dr. B. Dittrich, C. M. Wandtke, Dr. K. Pröpper, Dr. K. C. Mondal,

Dr. P. P. Samuel, N. Amin SK, Dr. A. P. Singh, Prof. Dr. H. W. Roesky,

Dr. N. Sidhu

Institut für Anorganische Chemie

Georg-August-Universität

Tammannstrasse 4

37077 Göttingen (Germany)

[c] Dr. A. Meents

Deutsches Elektronensynchrotron DESY

Notkestrasse 85

22607 Hamburg Germany

$\left.{ }^{+}\right]$K.P. passed away during the preparation of this manuscript.

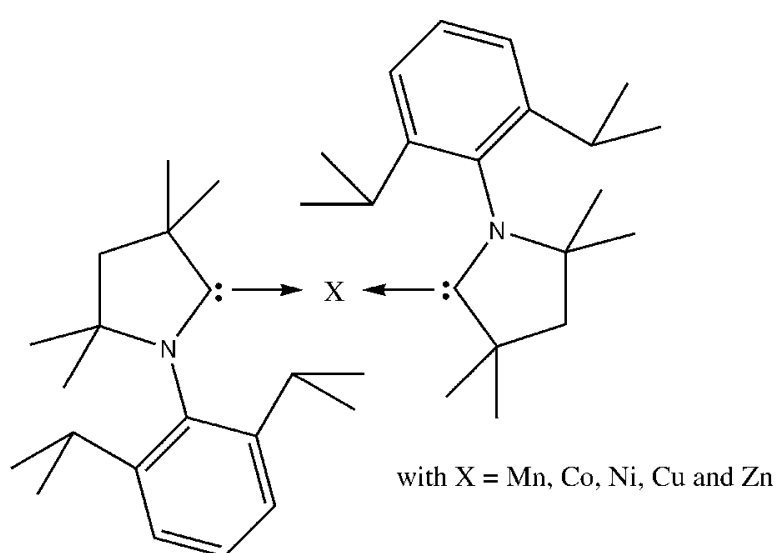

Figure 1. Schematic representation of the (CAAC) $\mathrm{X}$ two-coordinate carbene complexes studied. CAAC $=$ cyclic alkylaminocarbene [3,3,5,5-tetramethyl-1(2,6-diisopropylphenyl)pyrrolidine-2-ylidene].

using the IAM without prior chemical knowledge. We observe that, for example, $\mathrm{Cu}$ instead of $\mathrm{Zn}$ or $\mathrm{Ni}$ instead of $\mathrm{Cu}$ gives a better fit to the diffraction data in the $\mathrm{IAM}^{2}$ although the

\footnotetext{
Depending on anomalous dispersion of the central atom at a particular wavelength, especially near the absorption edge, the element right of the correct one may be found by using the IAM.

Anomalous dispersion effects close to the absorption edge of the central element can complicate and even reverse the situation. This is studied in Section 3.7 .
} 
heavier element is unambiguously present ${ }^{3}$ rearrangements in the aspherical valence electron-density distribution (EDD) forbid reliable distinguishing and correct identification of the metal atom in such coordination compounds with conventional methodology. These findings clearly illustrate the need to sometimes go beyond the spherical-atom IAM approximation and led us to investigate whether the use of invariom aspherical scattering factors can provide a remedy.

Invarioms ${ }^{[8]}$ are tabulated aspherical scattering factors that, given the same bonding environment, are transferable from one molecule to another. Structure refinement with invarioms has recently been generalized ${ }^{[9]}$ to cover first- and second-row elements commonly found in organic compounds. To achieve generalization of the invariom database it was necessary to develop, test, and validate a number of empirical rules that ensure transferability of electron density in real space. These rules also permit the tabulation of scattering factors in reciprocal space. An underlying requirement for transferability of electron density is that bond distances and angles to neighboring atoms of a pseudoatom ${ }^{[10]}$ fragment of the Hansen/Coppens multipole mode ${ }^{[11]}$ must be in close resemblance. This basic requirement is frequently violated in coordination compounds with similar chemical environments, as inner-shell electrons may or may not be involved in bonding, and this leads to reduced directionality.

The invariom database does, therefore, not include scattering factors for d-block elements. ${ }^{4}$ The statistically larger number of bonding situations and isomers involving $d$-block metal atoms compared to first- and second-row elements is another reason why these elements were so far excluded from the database. This larger number renders a database approach unsuited for covering such chemical environments. Earlier attempts for investigating organometallic compounds by aspherical-atom refinement with theoretically predicted scattering factors were hence based on either geometry optimization of complete molecules ${ }^{[15]}$ or hybrid theoretical/experimental refinement, as in the case of vitamin $B_{12}{ }^{[16]}$ In the latter case, multipole parameters were initially predicted by using the invariom database and were kept fixed for atoms in disordered solvent molecules. In addition, individual stockholder-based radial functions of the $C_{0}$ atom in vitamin $B_{12}$ were introduced to better fit the bonding environment. A hybrid approach in a charge-density study with fixed and refined multipole populations was also recently adapted for disordered functional groups in the molecular periphery of a hexasilabenzene derivative. ${ }^{[17]}$

Accurate crystallographic studies of metal-containing compounds provide challenges for experiment and modeling. Absorption and extinction are two examples of possible experi-

\footnotetext{
${ }^{3}$ This is known from combined spectroscopic evidence from the starting material used in the synthesis and, for the Ni and Cu compounds, also from a fluorescence scan with synchrotron radiation at the absorption edge.

${ }^{4}$ The fact that the basis set $D 95++(3 d f, 3 p d)^{[22]}$ was used so far also limited application to elements up to argon. We therefore reoptimized the model compounds of the invariom database with the TZVP basis set ${ }^{[13]}$ in combination with the MO6 functiona ${ }^{[74]}$ to be able to change this situation.
}

mental complications, and so is the occurrence of anharmonic thermal motion $;^{[18,19]}$ the presence of undetected structural disorder can also invalidate results of experimental charge-density studies, ${ }^{[20-22]}$ as the refined multipole populations correlate with occupancies of split atoms and can therefore not be determined reliably. Disorder also prohibits, at the current stage, Hirshfeld-atom refinement (HAR), ${ }^{[23,24]}$ and subsequent $X$-ray wavefunction refinement. ${ }^{[25,26]}$ Examples of modeling challenges encountered include the dominance of core over valence scattering ${ }^{[27-29]}$ and inaccurate radial functions ${ }^{[30,3115}$ of the Hansen/Coppens multipole model. A detailed discussion of these and other related issues was recently given by Schmøkel et al. ${ }^{[32]}$ However, omitting disordered and/or metal-containing structures from aspherical-atom modeling altogether would, from a scientific interest point of view, be clearly limiting and unsatisfactory. It is in fact d-block chemistry for which crystallography can frequently make a significant contribution to solving questions in theoretical and applied chemistry, as the EDD $\rho(\mathbf{r})$ can be observed experimentally. Charge-density research on metal-containing compounds $s^{[33]}$ therefore has a large overlap with theoretical chemistry, for which challenges are related to the growing expense of computer time with increasing model sophistication. Single-crystal X-ray diffraction shows no similar limitation and can, in favorable cases, for example, if minimal extinction synchrotron data are available, even provide experimental reference results on the electronic structure of metal-containing compounds; ${ }^{[34]}$ the correct choice of wavelength to avoid a strong influence of anomalous dispersion is especially relevant in this respect (see Section 3.1).

The topic of this paper ultimately goes beyond element assignment in XRD, as indirectly probing the aspherical electron density of metal-containing compounds by comparing theory and experiment can be useful in several other applications, for example, to validate DFT computations with high-quality $\mathrm{X}$-ray data. One example is given at the end of the paper, and we will further exploit these ideas in subsequent work. Next, a general procedure to model conventional single-crystal X-ray diffraction data of $d$-block coordination compounds with aspherical atoms is presented.

\section{An Aspherical Scattering Factor Model for Metal-Organic Compounds}

There are several requirements that a refinement aiming to replace the IAM for organometallic compounds would ideally fulfill routinely. These are:

1. The refinement procedure should give results that are superior to those provided by the IAM.

2. The method should provide benefits similar to those of invariom refinement of organic compounds: that is, deconvo-

\footnotetext{
An m-dependence of the radial functions would be preferable to the current $\mathrm{n}$-dependence (quantum numbers). We think that considerable progress in modeling d-block coordination compounds is nevertheless possible.
} 
lution of electron density and thermal motion to yield physically meaningful atomic displacement parameters (ADPs), lower standard uncertainties of refined parameters, and better figures of merit.

3. Calculation of aspherical scattering factors should be rapid and feasible on a current desktop computer (not only on a supercomputer), so that the size of the system under study is not compromised by computational requirements. The current procedure for tabulating scattering factors of the invariom database, which relies on time-consuming geometry optimizations and subsequent frequency calculations, does not fulfill this.

4. The same model accuracy/sophistication should be used for all atoms in a crystal structure, that is, scattering factors should be available for all atoms involved, not just the ligand environment.

5. The method should be forgiving as far as data quality and resolution are concerned. In that respect it should be similar to the invariom approach, for which meeting resolution requirements of the Journal Acta Crystallographica Section C is sufficient; retrospective application to published structures with deposited diffraction data should be possible.

6. Disordered structures should be refinable.

7. Eventually, the procedure should (after testing and further development) be as robust as the IAM in its application.

The invariom approach, HAR, and all other methods cannot meet all of these requirements at the current stage.

\subsection{Technical Procedure}

A technical procedure that would enable meeting the abovementioned requirements is as follows: An initial structural model is provided by IAM refinements, as performed, for example, with SHELXL ${ }^{[35]}$ in combination with the graphical user interface SHELXLE, ${ }^{[36]}$ with CRYSTALS ${ }^{[37]}$ or with OLEX2. ${ }^{[38]}$ Invariom names and database scattering factors are assigned to non-metal atoms in a following step. Whereas the invariom database does not provide valence density parameters of metal atoms, the ligand environment and other parts of a metal-organic structure can already be treated-as long as they contain only the elements $\mathrm{C}, \mathrm{H}, \mathrm{N}, \mathrm{O}, \mathrm{F}, \mathrm{S}$, and $\mathrm{P}$; bonds to metal atoms are ignored for generating the invariom name in this step. Whereas the structural model so generated does not completely cover the entire nonspherical EDD of a hypothetical molecule, preliminary refinement nevertheless provides a suitable geometry for subsequent theoretical calculations by taking into account ligand-atom asphericity shifts, ${ }^{[39]}$ which do not affect the position of metal atoms (and their higher core density) very much. Most important is that bond lengths to hydrogen atoms are elongated to values from the invariom database during this preliminary refinement. This leads to a considerable lowering of the single-point energy. Such preliminary refinement will hence give a superior structure for a single-point energy computation than the IAM refinement, despite the fact that the asphericity of metal atoms is not yet taken into account. A single-point energy calculation is computationally un- demanding ${ }^{6}$ and yields a molecular EDD that can be subjected to scattering-factor generation ${ }^{7}$ by analytical Fourier transform. ${ }^{[43]}$ For the latter, all-electron basis sets are required. At this stage several models of the spin or ionization states of the metal atom can be generated and compared, and the correct one can be determined. We note in passing that polymeric structures are excluded, as a molecular wavefunction is required. Structures with more than one molecule in the asymmetric unit $\left(Z^{\prime}>1\right)$ do not pose an additional challenge but may require several single-point computations. Solvent molecules covered in the invariom database can be modeled directly, as TZVP database entries have now been computed with the same method/basis set combination that was used for the single-point computation. ${ }^{8}$

Moreover, the application of symmetry can be necessary, for example, if one or several atoms in a molecule under study reside on a special position. This can be conveniently achieved by using PLATON ${ }^{[44]}$ but would need to be coded properly for routine application. Next, a local scattering-factor database is created by using invariom names of all atoms, and an aspherical-atom refinement is performed. Such a refinement now fulfills most of the requirements outlined in Section 2; probing the metal spin and ionization state with the experimental data and different local databases is often possible even if data quality and resolution do not meet the requirements for a charge-density study. ${ }^{[45,46]}$ Given that in an all-pseudoatom refinement the geometry might again improve slightly with respect to intermediate refinement (which covers the aspherical electron density of the organic part of a molecule only), one should ensure that the cycle of single-point calculation, Fourier transform, local database generation, and aspherical-atom refinement converges. This was achieved herein by automating and repeating these steps with a Linux shell script. The technical procedure outlined above is amenable to frequent application and minimizes modeling challenges in charge-density research caused by radial functions, ${ }^{[30,31]}$ absorption, extinction, and parameter correlation, as the EDD is fixed. Indirect probing of different theoretical models with experimental data can be achieved by using the same tools [especially Invariom Tool] ${ }^{[47]}$ that were created for invariom modeling and for establishing the invariom database: projecting ${ }^{9}$ one or several theoretical electron-density models onto the multipole model to fit experimental data can then provide indirect proof of the validity of the best out of several models. Another advantage of this indirect approach is that it can also be used for disordered compounds in combination with conventional X-ray data of normal

\footnotetext{
${ }^{6}$ The resolution of identity ${ }^{[40,41]}$ approximation can reduce the computational requirements even further.

This can be achieved either by Fourier transform to give simulated structure factors that can then be fitted with a multipole model or by a direct space fit. $^{[42]}$

${ }^{8}$ This requirement is less important than in a direct quantum chemical treatment, as projection onto the Hansen/Coppens multipole model ensures that the scattering-factor model is the same even with different basis sets.

"The terminology "projection" onto the multipole model was introduced by Koritsánszky et al. ${ }^{[48]}$ and, in this context, means the process of reproducing theoretical EDD through least-squares fit of multipole parameters.
} 
resolution $\left(\sin \theta / \lambda \approx 0.6 \AA^{-1}\right)$, because a single-point calculation with conventional $\mathrm{X}$-ray data of a nondisordered molecule provides scattering factors also for all parts of disordered atoms. Technical details to facilitate invariom modeling of disordered structures will be elaborated in another paper.

\subsection{Beyond the Hansen/Coppens Multipole Model}

We note that the procedure outlined in Section 2.1 is conceptually very similar to the steps involved in $\mathrm{HAR}^{[23,24]}$ which is superior in an important aspect: the physical foundation of the scattering model is sound in HAR, and it allows an increase in the sophistication of the basis set that the scattering factor is based upon. This circumvents limitations of the Hansen/Coppens multipole model. ${ }^{[49]}$ However, there are two caveats: first, HAR requires repeated computation of a wavefunction of the entire system (e.g. main molecule and solvent), and computational requirements are a limitation in applications of HAR to routine structure refinement; second, disordered structures cannot be handled with HAR at the current stage, which would be required for practical application in conventional structure analysis; this is being developed. Implementing a database approach with a basis-set EDD representation in HAR would therefore be very desirable. At the current stage, resolving these and other technical issues, for example, probing or validating spin and oxidation states, is technically easier with the XD suite of programs.

\section{Experimental Section}

Five datasets of recently synthesized chemically interesting neutral $3 \mathrm{~d}$ metal carbene complexes $(\mathrm{CAAC})_{2} \mathrm{X}$ with $\mathrm{X}=\mathrm{Mn}, \mathrm{Co}, \mathrm{Ni}, \mathrm{Cu}$, and $\mathrm{Zn}$ were investigated in this work. Recently, a cationic two-coordinate iron complex with the same ligand was synthesized, ${ }^{[6,7]}$ but we focused on neutral complexes herein. The three (CAAC) $)_{2} \mathrm{Mn} / \mathrm{Cu} /$ $\mathrm{Zn}$ structures show linear coordination. ${ }^{[1,2,4]}$ Structures with $\mathrm{Mn}, \mathrm{Ni}$, and $\mathrm{Cu}$ are toluene solvates, the $\mathrm{Co}$ structure is a THF hemisolvate, and for the $\mathrm{Zn}$ compound a desolvate was characterized. ${ }^{[1]}$ The $\mathrm{Co}$ and $\mathrm{Ni}$ compounds show deviation from ideal linear coordination, ${ }^{[2,5]}$ and they have attracted interest for their catalytic activity. ${ }^{[3]}$ Details of the experimental data collections and structure determinations of all five structures have been reported, including the original data collection of the Ni complex with CuK radiation. X-ray intensity data were also deposited embedded together with SHELXL2013 instruction files in the CIF file [CCDC-925860 (Mn compound), -994098 (Co compound), and -934645 ( $\mathrm{Ni}$ compound) contain supplementary crystallographic data for the abovementioned earlier publications]. $\mathrm{Cu}$ and $\mathrm{Zn}$ compounds were published as Supporting Information, again including intensities. These data were then merged for use with the XDLSM program and were further evaluated. The $(\mathrm{CAAC})_{2} \mathrm{Mn}$ data set was reintegrated, which gave an improved $R_{1}(F)$ of 5.5 rather than $5.9 \%$ for IAM refinement with SHELXL2013. To study a possible influence of anomalous dispersion, we additionally performed a series of experiments on $(\mathrm{CAAC})_{2} \mathrm{Ni}$ at photon energies of $26,19,16$, and $13 \mathrm{keV}$, which correspond to wavelengths of $0.4769,0.6523,0.7749$, and $0.9537 \AA$, respectively, at the PX beamline of the Petralll synchrotron (DESY, Hamburg). Due to the size of the Pilatus $6 \mathrm{M}$ detector, fulfilling the resolution requirements for a charge-density study became feasible with the shortest of these wavelengths. We performed these experiments at a temperature of $(23 \pm 2) \mathrm{K}$ with the aid of a Cryosystems of America open-flow helium low-temperature device to minimize solvent disorder. The XDS program ${ }^{[50]}$ was used for data integration, and SADABS ${ }^{[51]}$ was used for scaling. The detector distance was maintained at $134.60 \mathrm{~cm}$. The compounds are air sensitive. Crystals for all earlier and additional experiments were hence mounted under an inert gas atmosphere, directly put into Paratone $\mathrm{N}$ oil, subsequently frozen in liquid nitrogen in a storage Dewar, and mounted on the diffractometer maintaining cryogenic temperature. Crystallographic details for the new multiwavelength $(\mathrm{CAAC})_{2} \mathrm{Ni}$ data and the improvements seen between IAM and aspherical-atom refinements are given in Table 1; dataset statistics for the already published data set measured with CuK $\alpha$ are given for comparison.

\section{Crystallographic Refinements and Computational Details}

For aspherical-atom refinements we followed the procedure described in Section 2.1: initial least-squares refinements were performed with SHELXL, ${ }^{[35]}$ which thereby provided input coordinates for subsequent cycles of IAM and aspherical-atom refinements with the XDLSM program, ${ }^{[52]}$ version 6.03 . These refinements employed reflections with $1>2 \sigma(l)$ and included negative intensities for the calculation of $R_{1}(F)$; systematic absences were removed by SADABS, and a SHELXL-type weighting scheme was used to allow direct comparison. In the invariom-refinement step, bond distances to $\mathrm{H}$ atoms were set to values for the respective optimized invariom model compound [method/basis set: B3LYP/D95 $++(3 \mathrm{df}, 3 \mathrm{pd}$ ), program Gaussian 09]. ${ }^{[53]}$ Positions of the $\mathrm{H}$ atoms were placed with SHELXL and were then constrained in a riding hydrogen model also in XD; $\mathrm{H} U_{\text {iso }}$ were adjustable parameters. Constraints for XDLSM were generated with the program Invariom Tool. ${ }^{[47]}$ "Whole-molecule" aspherical scattering factors were obtained by single-point computation with the M06/TZVP method ${ }^{[14]} /$ basisset $^{[13]}$ combination. Subsequent Fourier transform ${ }^{[43]}$ and projection onto the multipole model allowed a tailor-made local scattering factor database to be generated for the respective molecule. Re-refinement with starting coordinates taken from the invariom step was performed to convergence by repeating the cycle of singlepoint computation, database generation, and refinement. ADPs of disordered toluene atoms were treated as a rigid body by invoking the KEEP RIGID command in XD in the (CAAC) $2 \mathrm{Mn} / \mathrm{Ni} / \mathrm{Cu}$ solvate structures. As mentioned above, Table 1 lists the results from XD IAM and aspherical-atom refinements. CIF files for multiwavelength aspherical-atom refinements of $(\mathrm{CAAC})_{2} \mathrm{Ni}$ with $\mathrm{XD}$ were deposited at the CCDC. CCDC-934645, -1018228, -1018229, -1018230, and -1018231 contain the supplementary crystallographic data for this paper. These data can be obtained free of charge from The Cambridge Crystallographic Data Centre via www.ccdc.cam.ac.uk/data request/cif.

\section{Results and Discussion}

We initiated this study motivated by knowing that from synthesis we had $\mathrm{Ni}$ as a central metal atom in (CAAC) $)_{2} \mathrm{Ni}$ and by observing that $\mathrm{Cu}$ scattering factors gave a better $R_{1}(F)$ in the IAM refinement with SHELXL. An analogous observation, that is, that the wrong element gives a better fit to the diffraction data, was then made with several linear-coordinate metal complexes, albeit with the element left of the correct one, and this latter finding is readily explained by the characteristics of the cyclic alkylaminocarbene ligand: ${ }^{[54]}$ stabilization of unusual 


\begin{tabular}{|c|c|c|c|c|c|}
\hline \multicolumn{6}{|l|}{ Crystal data } \\
\hline chemical formula & $2\left(\mathrm{C}_{40} \mathrm{H}_{62} \mathrm{~N}_{2} \mathrm{Ni}\right) \cdot \mathrm{C}_{7} \mathrm{H}_{8}$ & & & & \\
\hline formula weight & 1351.35 & & & & \\
\hline cell setting, space group & triclinic, $P \overline{1}$ & & & & \\
\hline temperature $[\mathrm{K}]$ & 23 & & & & 100 \\
\hline$a[\AA]$ & $9.1131(10)$ & $9.1195(7)$ & $9.1190(14)$ & $9.118(2)$ & $9.1361(18)$ \\
\hline$c[\AA]$ & $18.497(4)$ & $18.500(3)$ & $18.510(4)$ & $18.503(6)$ & $18.538(4)$ \\
\hline$\alpha[\AA]$ & $79.238(19)$ & $79.260(12)$ & $79.24(2)$ & $79.26(2)$ & $79.22(3)$ \\
\hline$\beta[\AA]$ & $76.47(2)$ & $76.52(2)$ & $76.467(18)$ & $76.48(2)$ & $76.32(3)$ \\
\hline$\gamma[\AA]$ & $89.35(3)$ & $89.42(4)$ & $89.33(3)$ & $89.39(2)$ & $89.36(3)$ \\
\hline$V\left[\AA^{3}\right]$ & $1953.9(7)$ & $1957.2(5)$ & $1957.5(8)$ & $1956.6(10)$ & $1965.4(7)$ \\
\hline$Z, F(000)$ & 4738 & & & & \\
\hline$D_{x}\left[\mathrm{Mg} \mathrm{m}^{-3}\right]$ & 1.149 & 1.147 & 1.146 & 1.147 & 1.142 \\
\hline$\lambda[\AA]$ & 0.4769 & 0.6523 & 0.7749 & 0.9537 & 1.5418 \\
\hline$\mu\left[\mathrm{mm}^{-1}\right]$ & 0.238 & 0.418 & 0.902 & 1.149 & 0.922 \\
\hline crystal form, color & & & rectangular, black & & \\
\hline crystal size $\left[\mathrm{mm}^{3}\right]$ & $0.175 \times 0.045 \times 0.033$ & & & & $0.65 \times 0.20 \times 0.18$ \\
\hline \multicolumn{6}{|l|}{ Data collection } \\
\hline diffractometer & piezodiffracton & ter @ PX11 & & & Bruker Smart 6000 \\
\hline data collection method & $\phi$ scans & & & & $\omega$ and $\phi$ scans \\
\hline absorption correction & empirical & & & & \\
\hline$T_{\min }, T_{\max }$ & $0.3874 / 0.4112$ & $0.4038 / 0.4282$ & $0.3985 / 0.4313$ & $0.4018 / 0.4314$ & $0.5737 / 0.7532$ \\
\hline no. of measured, & 157134 & 64666 & 17422 & 8161 & 62148 \\
\hline independent reflections & 30298 & 11719 & 6669 & 3352 & 7063 \\
\hline observed reflections & 23856 & 11284 & 6636 & 3349 & 6988 \\
\hline criterion for observed reflections & $1>2 \sigma(l)$ & & & & \\
\hline$R_{\mathrm{int}}[\%]$ & 0.0633 & 0.0483 & 0.0326 & 0.0207 & 0.0308 \\
\hline$\theta_{\max }\left[{ }^{\circ}\right],(\sin \theta / \lambda)_{\max }$ & $28.56,1.00$ & $28.53,0.73$ & $27.71,0.62$ & $34.91,0.5$ & $68.2,0.60$ \\
\hline \multicolumn{6}{|c|}{ IAM/aspherical-atom refinement with invarioms } \\
\hline refinement on & $F^{2}$ & & & & \\
\hline$R_{1}[l>2 \sigma(l)]$ & $0.043 / 0.037$ & $0.033 / 0.025$ & $0.039 / 0.031$ & $0.031 / 0.021$ & $0.032 / 0.020$ \\
\hline no. of reflections & 23856 & 11284 & 6636 & 3349 & 6988 \\
\hline $\mathrm{H}$ atom treatment & \multicolumn{5}{|c|}{ invarioms: calculated $\mathrm{H}$-pos., bond-length elongated, $U_{\text {iso }}$ refined } \\
\hline Weighting scheme & & & & & \\
\hline $1 / \sigma^{2}\left(F_{0}^{2}\right)+[]\left(P=\frac{1}{3} F_{0}^{2}+\frac{2}{3} F_{c}^{2}\right)$ & {$\left[0.05 P^{2}+0.34 P\right]$} & {$\left[0.04 P^{2}+0.73 P\right]$} & {$\left[0.06 P^{2}+0.72 P\right]$} & {$\left[0.04 P^{2}+1.06 P\right]$} & {$\left[0.03 P^{2}+0.92 P\right]$} \\
\hline GOF & 1.79 & 2.31 & 2.90 & 2.95 & 3.40 \\
\hline GofW & 0.74 & 0.68 & 1.06 & 0.94 & 0.51 \\
\hline$\Delta \rho_{\max } / \Delta \rho_{\min }\left[\mathrm{e} \AA^{-3}\right]$ & $0.59 /-0.84$ & $0.40 /-0.56$ & $0.33 /-0.56$ & $0.11 /-0.13$ & $0.19 /-0.15$ \\
\hline
\end{tabular}

bonding situations is enabled by strong $\sigma$-donating and $\pi$-accepting capability in addition to steric hindrance. This causes electron deficiency at the metal center, as is apparent in the 3D deformation electron density plot by using DFT-derived scattering factors in Figure $2 b$ and the red Fourier residual electron density mesh in Figure $2 \mathrm{a}, \mathrm{c}$.

Figure 3 plots the improvement in the $R$ factor by comparing SHELXL IAM and XD aspherical-atom refinements: the use of scattering factors of the correct element gives $R_{1}(F)$ factors that are then compared to refinements by using the element left (green dots) and right (blue triangles) of the correct one (red cubes), this time by using the series of five neutral linear coordinate $(\mathrm{CAAC})_{2} \mathrm{X}$ complexes with $\mathrm{X}=\mathrm{Mn}, \mathrm{Co}, \mathrm{Ni}, \mathrm{Cu}$, and $\mathrm{Zn}{ }^{10}$ In all cases, the $\mathrm{X}$-ray wavelength has an energy higher than the absorption edge of the central metal atom present; for $(\mathrm{CAAC})_{2} \mathrm{Ni}$ the dataset at $19 \mathrm{keV}$ was chosen. Figure 3 clearly illustrates that all five compounds show the same behavior: most importantly, the incorrect element assignment with a scattering factor left to the correct one fits the diffraction data better than the correct one obtained by using the IAM. Figure 3 also includes results of the fit with aspherical scattering factors (black diamonds) for comparison, which gives the best fit in all five cases, which thereby enables the element present to be identified. If the wrong element is used in the aspherical-atom refinements a high penalty in the $R$ factor needs to be paid, and this may even lead to pathological ADPs

\footnotetext{
${ }^{10}$ A cationic (CAAC) ${ }_{2}$ Fe salt has been reported. ${ }^{[6,7]}$ We focus on neutral species herein. Recently, a neutral (CAAC), Fe salt has been described ${ }^{[55]}$ for which we expect analogous behavior.
} 
a)

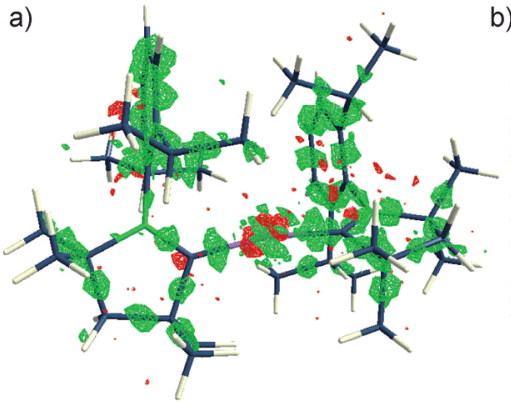

b)

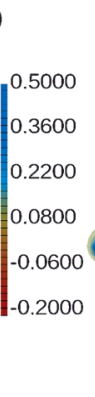

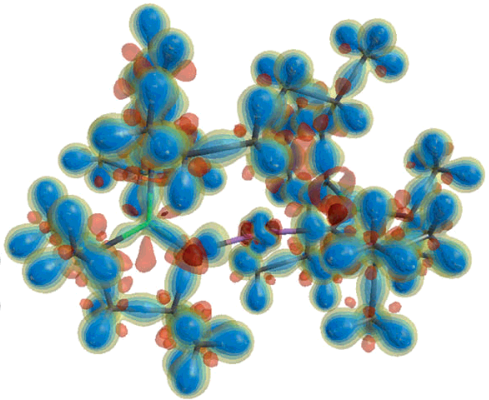

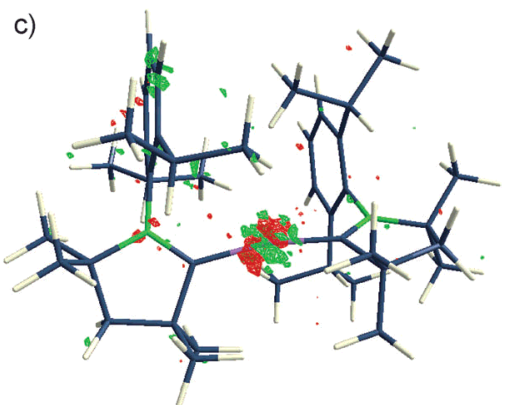

Figure 2. a) Fourier residual electron density map of (CAAC) ${ }_{2} \mathrm{Ni}$ after IAM refinement with XDLSM showing unmodeled bonding and lone-pair density. Electron density at the metal center (red mesh) that is redistributed towards the cyclic alkylaminocarbene ligand is also visible. b) 3D deformation electron-density plot of those contributions included in the aspherical scattering factor that are missing in the IAM. c) Nearly featureless Fourier map, after taking (b) into account. Isosurface meshes at 0.2 e $\AA^{-3}$ for (a) and (c). Isosurface values for (b) are given in the figure.

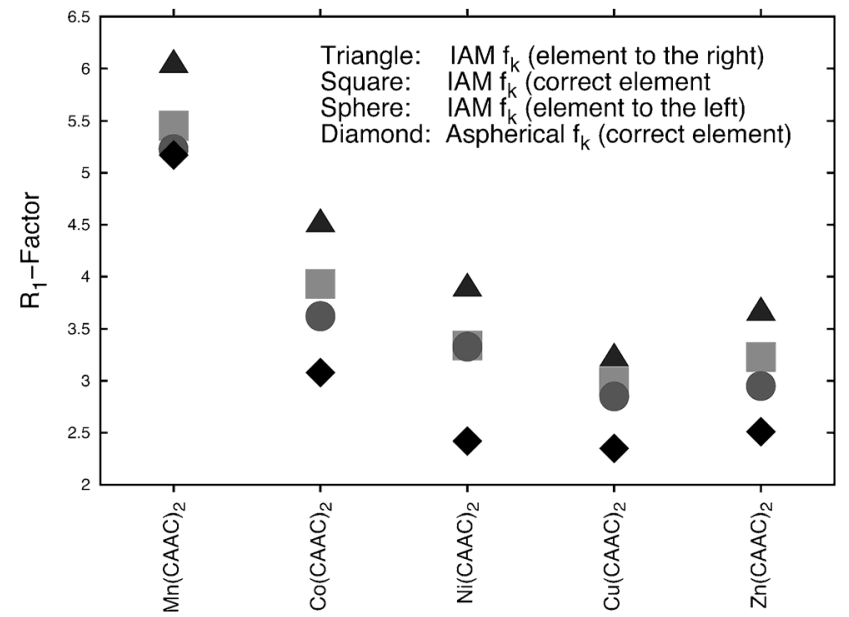

Figure 3. Crystallographic $R$ factor of refinements for five two-coordinate $(\mathrm{CAAC})_{2} \mathrm{X}$ complexes with $\mathrm{X}=\mathrm{Mn}, \mathrm{Co}, \mathrm{Ni}, \mathrm{Cu}$, and $\mathrm{Zn}$. The gray squares represent IAM refinements with the correct scattering factor, the triangles represent refinements with the correct element, and the spheres represent refinements with the element left of the correct one. The black diamonds are the $R$-factor results from aspherical-atom refinements, which always give the best result.

of the central atom. ${ }^{11} \mathrm{~A}$ distinction of the element is therefore directly evident with aspherical scattering factors. ${ }^{12}$

\subsection{The Role of Anomalous Dispersion}

We now focus on only one of the metal complexes: In the case of the nickel compound, $(\mathrm{CAAC})_{2} \mathrm{Ni}$, we studied the interesting situation for which the difference in the crystallographic $R_{1}$ factors in the IAM (calculated after SHELXL full-matrix leastsquares refinement) ${ }^{[35]}$ as defined in Equation (1) changes sign,

"The procedure described in Section 2.1 needs to be performed from scratch with the wrong element. This was only performed for the $\mathrm{Zn}$ compound. A further complication is that the number of electrons changes for adjacent elements, which renders multipole-type refinement cumbersome, as core and valence electrons are treated separately and need to be scaled to give the correct number of valence electrons.

${ }^{12}$ An indirect indication can also be gained from the single-point energy of the accompanying computation with a given set of coordinates. depending on the wavelength (photon energy) used.

$\Delta R(F)=R(F)_{\left[\mathrm{Co}_{0} \mathrm{Ni}\right]}-R(F)_{[\mathrm{Cu}-\mathrm{Ni}]}$

This leads to the confusing situation that, depending on the wavelength, sometimes $\mathrm{Co}$ instead of $\mathrm{Ni}$ and sometimes $\mathrm{Cu}$ instead of Ni scattering factors give a better $R_{1}$ factor in the IAM (Figure 4): upon using CuK $\alpha$ radiation, $\mathrm{Cu}$ scattering factors

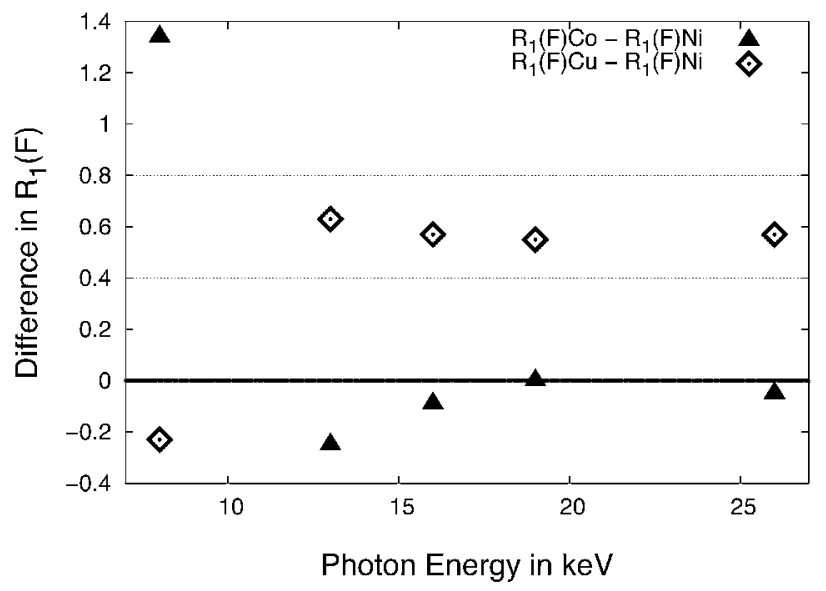

Figure 4. Differences in the crystallographic $R_{1}$ factor of the element left (Co) or right $(\mathrm{Cu})$ of the correct one (Ni) for two-coordinate (CAAC) $\mathrm{Ni}$ at different wavelengths from IAM refinements with the SHELXL program.

give a better $R$ factor, whereas for harder $\mathrm{X}$-rays, especially with $\lambda \leq 0.8 \AA$, the usual observation is made, that is, Co gives a better fit to the diffraction data than Ni. These observations were made after wavelength-dependent corrections for anomalous dispersion, as given in the International Tables for Crystallography, Volume $C$, were applied. A remedy if using the IAM would be either to measure diffraction data very close to the respective absorption edge, which usually requires tunable synchrotron radiation ${ }^{13}$ (and might not give acceptable data resolutions depending on the metal atom and beamline setup)

\footnotetext{
${ }^{13}$ In the home laboratory, users are usually limited to $\mathrm{Cu}, \mathrm{Ga}, \mathrm{Mo}$, and $\mathrm{AgK \alpha}$ radiation.
} 
a)

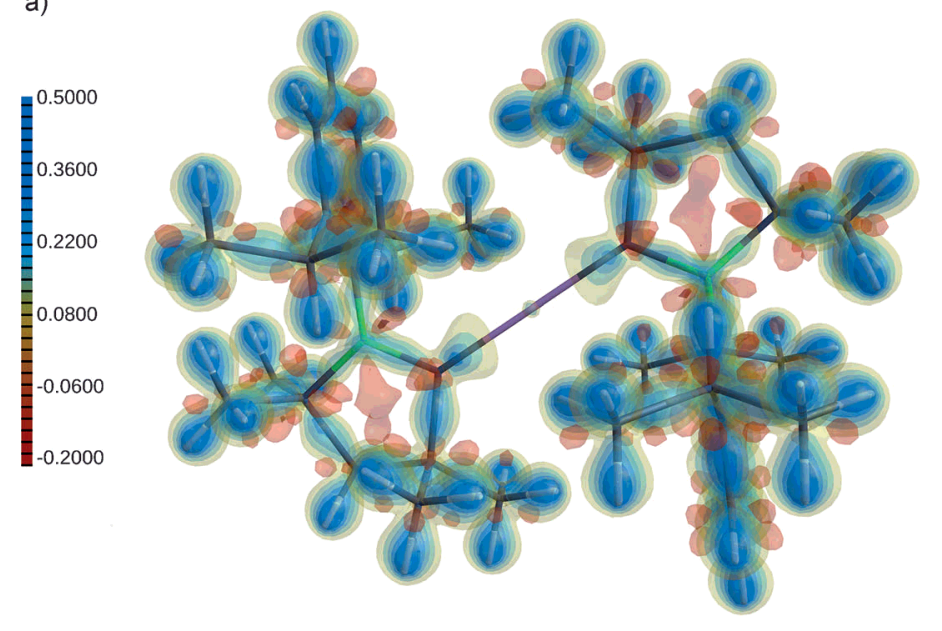

b)

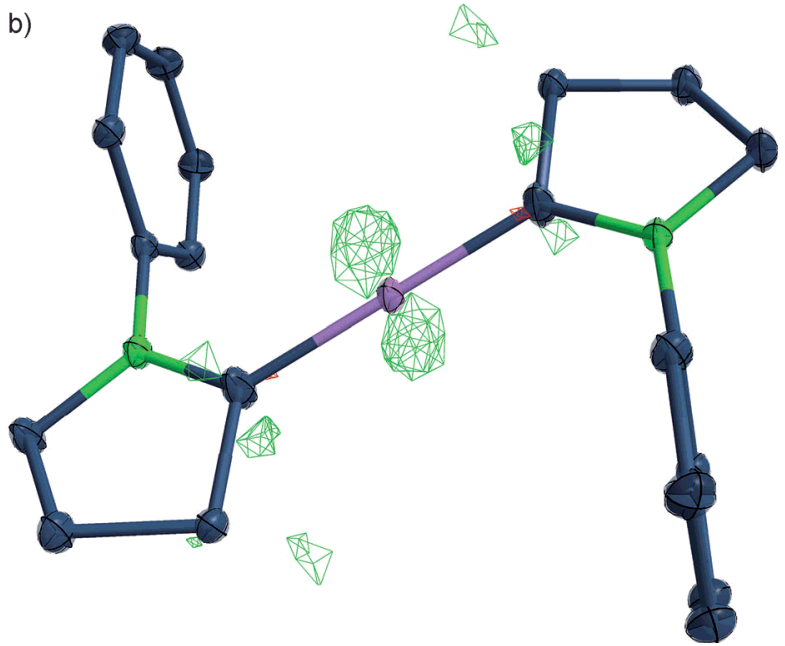

Figure 5. a) 3D deformation electron density plot illustrating electron deficiency at the metal center that is redistributed towards the cyclic alkylaminocarbene ligand in $(C A A C)_{2} Z n$. b) Residual electron density map of $(C A A C)_{2} Z n$ upon using Hansen/Coppens multipole model scattering factors from projecting of a theoretical M06/TZVP electron density. Deficiencies of the single-determinant wavefunction in describing the bonding situation are made clear by systematic green meshes above the carbene carbon and zinc atoms. Methyl, propyl, and disordered atoms are omitted for clarity. Isosurface mesh with 0.15 e $\AA^{-3}$.

or to use aspherical scattering factors, which consistently give the best $R_{1}$ factor, independent of the wavelength. To illustrate our findings, Figure 4 shows the difference $\Delta R(F)$ [see Eq. (1)] for $(\mathrm{CAAC})_{2} \mathrm{Ni}$ for different photon energies (wavelength, $\lambda$ ). A negative value implies that $R_{1}(\mathrm{~F})$ of the IAM gives the (wrong) element $\mathrm{Co}$, and a positive value indicates that the wrong element $\mathrm{Cu}$ is present, rather than $\mathrm{Ni}$. We expect both curves to cross around the K-absorption edge of nickel at $8.3328 \mathrm{keV}$, which is close to the data point on the left measured with CuK $\alpha$ radiation. As at high photon energies (herein 19 or $26 \mathrm{keV}$ ) more reflections can be collected, the difference that mainly affects low-order data becomes less significant, although artificially cutting the resolution allows the signal to be retrieved, which is also the case for high-resolution data sets.

It is well known in protein crystallography and in extended $\mathrm{X}$-ray absorption fine structure (EXAFS) studies that the direct chemical environment of the metal atom influences the shape and energy of the absorption edge. Re-distribution of EDD leads to interesting new applications of " $\mathrm{X}-\Psi^{2 \text { " }}$ and other difference-electron densities between synchrotron data collected near, above, and below the absorption edge; density redistributions near the metal atom are clearly not limited to core electron density but also affect valence electron density that can be modeled by multipole parameters. This will be further studied in a forthcoming paper with more suitable coordination complexes containing, for example, zirconium, ${ }^{14}$ for which the $\mathrm{K} \alpha$ absorption edge is situated at higher photon energies.

A first illustration of the potential utility of $X-\Psi^{2}$ difference density maps is shown for $(C A A C)_{2} Z n$ in Figure 5. High-level quantum chemical computations have shown that the bonding situation can only properly be explained by multireference wavefunctions. ${ }^{[1]}$ This information is also contained in the X-ray data: A simple Fourier map after refinement with scattering

\footnotetext{
${ }^{14}$ The all-electron def2SVP basis would allow the proposed procedure to be performed, respectively.
}

factors by using B3LYP/6-311G $(2 \mathrm{~d}, 2 \mathrm{p})$ and obtained by projecting the electron density onto the multipole model shows systematic residual electron density (positive in green, negative in red) above the carbene carbon and the zinc atoms.

\section{Conclusions and Outlook}

Reliability in element assignment based on figures of merit is an important fundamental in single-crystal X-ray diffraction, as reactants or solvent may contain impurities, and these often crystallize better than the desired product. Improving the capabilities of this method is therefore useful even if starting materials and/or products are known and other spectroscopic evidence is present.

The observation that it is difficult or impossible to unambiguously identify the element type of the metal atom in five linear-coordinate $3 \mathrm{~d}$ metal carbene complexes by using the independent atom model illustrates one of the limitations of this model. Aspherical scattering factors are shown to provide a remedy, which adds to earlier findings that they improve the physical significance of atomic displacement parameters, reduce the standard deviation of refined parameters, and avoid asphericity shifts to yield more accurate coordinates/ bond length; they simply give better structures. Taking aspherical electron density into account will therefore also be useful for other metal complexes and coordination compounds. Problems with element assignment are expected to be most pronounced in linear and square-planar compounds, but less so in tetrahedral and octahedral coordination environments, as the particular deviation from spherically symmetric electron-density distribution is the main underlying factor.

The suggested modeling procedure is widely applicable, based on the invariom database, and is amenable to d-block compounds in which all-electron calculations are technically feasible. It lends itself as a validation tool and does not require data collection to high resolution. 


\section{Acknowledgements}

B.D. acknowledges interesting and helpful discussions with G.M. Sheldrick, thanks F. P. A. Fabbiani for corrections in the manuscript, and is grateful to J.J. Holstein for help with preparing Figure 5.

Keywords: anomalous dispersion - carbenes - coordination compounds $\cdot$ density functional calculations $\cdot$ X-ray diffraction

[1] A. P. Singh, P. P. Samuel, H. W. Roesky, M. C. Schwarzer, G. Frenking, N. S Sidhu, B. Dittrich, J. Am. Chem. Soc. 2013, 135, 7324-7329.

[2] P. P. Samuel, K. C. Mondal, H. W. Roesky, M. Hermann, G. Frenking, S. Demeshko, F. Meyer, A. C. Stückl, J. H. Christian, N. S. Dalal, L. Ungur, L. F. Chibotaru, K. Pröpper, A. Meents, B. Dittrich, Angew. Chem. Int. Ed. 2013 52, 11817-11821; Angew. Chem. 2013, 125, 12033-12037.

[3] K. C. Mondal, P. P. Samuel, Y. Li, H. W. Roesky, S. Roy, L. Ackermann, N. S. Sidhu, G. M. Sheldrick, E. Carl, S. Demeshko, S. De, P. Parameswaran, L. Ungur, L. F. Chibotaru, D. M. Andrada, Eur. J. Inorg. Chem. 2014, 818823.

[4] D. S. Weinberger, N. A. SK, K. C. Mondal, M. Melaimi, G. Bertrand, A. C. Stückl, H. W. Roesky, B. Dittrich, S. Demeshko, B. Schwederski, W. Kaim, P. Jerabek, G. Frenking, J. Am. Chem. Soc. 2014, 136, 6235-6238.

[5] K. C. Mondal, S. Roy, S. De, P. Parameswaran, B. Dittrich, F. Ehret, W. Kaim, H. W. Roesky, Chem. Eur. J. 2014, 20, 11646-11649.

[6] Z. Mo, Z. Ouyang, L. Wang, K. Fillman, M. L. Neidig, L. Deng, Org. Chem Front. 2014, 1, 1040-1044.

[7] P. P. Samuel, K. C. Mondal, N. A. SK, H. W. Roesky, E. Carl, R. Neufeld, D. Stalke, S. Demeshko, F. Meyer, L. Ungur, L. F. Chibotaru, J. H. Christian, V. Ramachandran, J. van Tol, N.S. Dalal, J. Am. Chem. Soc. 2014, 136, 11964-11971

[8] B. Dittrich, T. Koritsánszky, P. Luger, Angew. Chem. Int. Ed. 2004, 43 2718-2721; Angew. Chem. 2004, 176, 2773-2776.

[9] B. Dittrich, C. B. Hübschle, K. Pröpper, F. Dietrich, T. Stolper, J. J. Holstein, Acta Crystallogr. Sect. B 2013, 69, 91 - 104.

[10] R. F. Stewart, Acta Crystallogr. Sect. A 1976, 32, 565-574.

[11] N. K. Hansen, P. Coppens, Acta Crystallogr. Sect. A 1978, 34, 909-921.

[12] T. H. Dunning, J. Chem. Phys. 1970, 53, 2823-2833.

[13] F. Weigend, R. Ahlrichs, Phys. Chem. Chem. Phys. 2005, 7, 3297-3305.

[14] Y. Zhao, D. G. Truhlar, Theor. Chem. Acc. 2008, 120, 215-241.

[15] R. S. Ghadwal, R. Azhakar, K. Pröpper, J. J. Holstein, B. Dittrich, H. Roesky, Inorg. Chem. 2011, 50, 8502-8508.

[16] B. Dittrich, T. Koritsánszky, S. Mebs, P. Luger, Angew. Chem. Int. Ed. 2007 46, 2935-2938; Angew. Chem. 2007, 119, 2993-2996.

[17] D. Kratzert, D. Leusser, J.J. Holstein, B. Dittrich, K. Abersfelder, D. Scheschkewitz, D. Stalke, Angew. Chem. Int. Ed. 2013, 52, 4478-4482 Angew. Chem. 2013, 125, 4574-4578.

[18] P. R. Mallinson, T. Koritsánszky, E. Elkaim, N. Li, P. Coppens, Acta Crystallogr. Sect. A 1988, 44, 336-342.

[19] R. Herbst-Irmer, J. Henn, J. J. Holstein, C. B. Hübschle, B. Dittrich, D. Stern, D. Kratzert, D. Stalke, J. Phys. Chem. A 2013, 117, 633-641.

[20] B. Dittrich, J. E. Warren, F. P. P. A. Fabbiani, W. Morgenroth, B. Corry, Phys. Chem. Chem. Phys. 2009, 17, $2601-2609$.

[21] J. M. Bak, P. M. Dominiak, C. C. Wilson, K. Wozniak, Acta Crystallogr. Sect A 2009, 65, 490-500.

[22] J. J. Holstein, P. Luger, R. Kalinowski, S. Mebs, C. Paulmann, B. Dittrich Acta Crystallogr. Sect. B 2010, 66, 568-577.

[23] D. Jayatilaka, B. Dittrich, Acta Crystallogr. Sect. A 2008, 64, 383-393.

[24] S. C. Capelli, H. B. Bürgi, B. Dittrich, S. Grabowsky, D. Jayatilaka, $N C r$ J 2014, 1, 361-379.

[25] D. Jayatilaka, Phys. Rev. Lett. 1998, 80, $798-801$.

[26] S. Grabowsky, P. Luger, J. Buschmann, T. Schneider, T. Schirmeister, A. N Sobolev, D. Jayatilaka, Angew. Chem. Int. Ed. 2012, 51, 6776-6779 Angew. Chem. 2012, 124, 6880-6884.

[27] E. D. Stevens, P. Coppens, Acta Crystallogr. Sect. A 1976, 32, 915-917.

[28] V. V. Zhurov, E. A. Zhurova, A. A. Pinkerton, J. Appl. Crystallogr. 2008, 41 $340-349$
[29] A. Fischer, D. Tiana, W. Scherer, K. Batke, G. Eickerling, H. Svendsen, N Bindzus, B. Iversen, J. Phys. Chem. A 2011, 115, $13061-13071$

[30] B. N. Figgis, B. B. Iversen, F. K. Larsen, P. A. Reynolds, Acta Crystallogr Sect. B 1993, 49, 794-806.

[31] A. Volkov, P. Coppens, Acta Crystallogr. Sect. A 2001, 57, 395-405.

[32] M. S. Schmøkel, J. Overgaard, B. B. Iversen, Z. Anorg. Allg. Chem. 2013, 639, 1922-1932.

[33] P. Macchi, A. Sironi, Coord. Chem. Rev. 2003, 238-239, 383-412.

[34] M. S. Schmøkel, L. Bjerg, J. Overgaard, F. K. Larsen, G. K. H. Madsen, K. Sugimoto, M. Takata, B. B. Iversen, Angew. Chem. Int. Ed. 2013, 52, 1503-1506; Angew. Chem. 2013, 125, 1543-1546.

[35] G. M. Sheldrick, Acta Crystallogr. Sect. A 2008, 64, 112-122.

[36] C. B. Hübschle, G. M. Sheldrick, B. Dittrich, J. Appl. Crystallogr. 2011, 44, $1281-1284$

[37] P. W. Betteridge, J. R. Carruthers, R. I. Cooper, K. Prout, D. J. Watkin, J. Appl. Crystallogr. 2003, 36, 1487.

[38] O. V. Dolomanov, L. J. Bourhis, R. J. Gildea, J. A. K. Howard, H. Puschmann, J. Appl. Crystallogr. 2009, 42, 339-341.

[39] P. Coppens, T. M. Sabine, R. G. Delaplane, J. A. Ibers, Acta Crystallogr. Sect. B 1969, 25, $2451-2458$.

[40] E. J. Baerends, P. Ros, Chem. Phys. 1973, 2, 41-51.

[41] C.-K. Skylaris, L. Gagliardi, N. Handy, A. Ioannou, S. Spencer, A. Willetts, J. Mol. Struct. THEOCHEM 2000, 501, 229-239.

[42] T. Koritsanszky, A. Volkov, C. Chodkiewicz, Struct. Bonding 2012, 147, 1 -

[43] D. Jayatilaka, Chem. Phys. Lett. 1994, 230, $228-230$.

[44] A. L. Spek, Acta Crystallogr. Sect. D 2009, 65, 148-155.

[45] R. H. Blessing, C. Lecomte in The Application of Charge Density Research to Chemistry and Drug Design, Plenum, New York, 1991, pp. 155-185.

[46] T. Koritsanszky, R. Flaig, D. Zobel, H.-G. Krane, W. Morgenroth, P. Luger, Science 1998, 279, 356-358.

[47] C. B. Hübschle, P. Luger, B. Dittrich, J. Appl. Crystallogr. 2007, 40, 623627.

[48] T. Koritsanszky, A. Volkov, P. Coppens, Acta Crystallogr. Sect. A 2002, 58 $464-472$.

[49] L. Chęcinska, W. Morgenroth, C. Paulmann, D. Jayatilaka, B. Dittrich, CrystEngComm 2013, 15, 2084-2090.

[50] W. Kabsch, Acta Crystallogr. D 2010, 66, 125-132.

[51] G. M. Sheldrick, SADABS (version 2014/1): A Program for Area Detector Absorption and Other Corrections, technical report, University of Göttingen, Göttingen, 2014

[52] A. Volkov, P. Macchi, L. J. Farrugia, C. Gatti, P. Mallinson, T. Richter, T. Koritsánszky, XD2006-A Computer Program Package for Multipole Refinement, Topological Analysis of Charge Densities and Evaluation of intermolecular Energies from Experimental or Theoretical Structure Factors, 2006.

[53] Gaussian 09 (revision D.01), M. J. Frisch, G. W. Trucks, H. B. Schlegel, G. E. Scuseria, M. A. Robb, J. R. Cheeseman, G. Scalmani, V. Barone, B. Mennucci, G. A. Petersson, H. Nakatsuji, M. Caricato, X. Li, H. P. Hratchian, A. F. Izmaylov, J. Bloino, G. Zheng, J. L. Sonnenberg, M. Hada, M. Ehara, K Toyota, R. Fukuda, J. Hasegawa, M. Ishida, T. Nakajima, Y. Honda, O. Kitao, H. Nakai, T. Vreven, J. A. Montgomery, Jr., J. E. Peralta, F. Ogliaro, M. Bearpark, J. J. Heyd, E. Brothers, K. N. Kudin, V. N. Staroverov, R. Ko bayashi, J. Normand, K. Raghavachari, A. Rendell, J. C. Burant, S. S. Iyengar, J. Tomasi, M. Cossi, N. Rega, J. M. Millam, M. Klene, J. E. Knox, J. B. Cross, V. Bakken, C. Adamo, J. Jaramillo, R. Gomperts, R. E. Stratmann, O. Yazyev, A. J. Austin, R. Cammi, C. Pomelli, J. W. Ochterski, R. L. Martin, K. Morokuma, V. G. Zakrzewski, G. A. Voth, P. Salvador, J. J. Dannenberg S. Dapprich, A. D. Daniels, Ö. Farkas, J. B. Foresman, J. V. Ortiz, J. Cioslowski, and D. J. Fox, Gaussian, Inc., Wallingford CT, 2009.

[54] V. Lavallo, Y. Canac, C. Präsang, B. Donnadieu, G. Bertrand, Angew. Chem. Int. Ed. 2005, 44, 5705-5709; Angew. Chem. 2005, 117, 5851 5855.

[55] G. Ung, J. Rittle, M. Soleilhavoup, G. Bertrand, J. C. Peters, Angew. Chem Int. Ed. 2014, 53, 8427-8431; Angew. Chem. 2014, 126, 8567-8571

Received: August 25, 2014

Revised: September 13, 2014

Published online on $\square \mathbf{~ I I , ~} 2014$ 


\section{ARTICLES}

Modeling gig: A computationally efficient procedure for aspherical-atom least-squares refinement of conventional diffraction data of organometallic compounds is proposed. Five linear-coordinate $3 \mathrm{~d}$ metal complexes are studied. It is shown that only asphericalatom scattering factors allow reliable assignment of the element. The influence

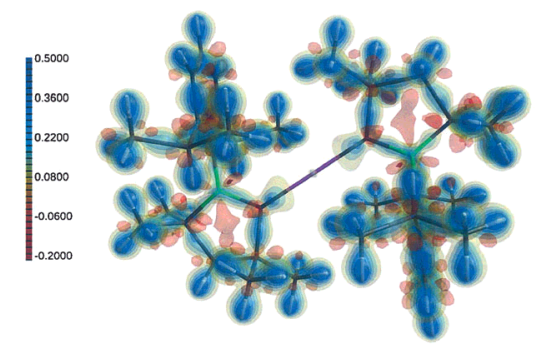

B. Dittrich, ${ }^{*}$ C. M. Wandtke, A. Meents, K. Pröpper, K. C. Mondal, P. P. Samuel, N. Amin SK, A. P. Singh, H. W. Roesky, N. Sidhu

$-\square$

Aspherical-Atom Modeling of Coordination Compounds by SingleCrystal X-ray Diffraction Allows the Correct Metal Atom To Be Identified

the correct element is investigated and discussed. 